\title{
Soil conditions and bounds to suction during the installation of caisson foundations in sand
}

\author{
Ouahid Harireche*, Moura Mehravar, Amir M. Alani \\ Department of Civil Engineering, Medway School of Engineering, Central Avenue, Chatham Maritime, University of Greenwich, Kent ME4 4TB, UK.
}

\section{A R T I C L E I N F O}

\section{Keywords:}

Caisson foundation

Installation in sand

Normalised geometry

Piping condition

Failure modes

\begin{abstract}
A B S T R A C T
Suction installation of caisson foundations is widely adopted in the oil offshore industry. When such foundations are installed in sand, seepage conditions are known to play a pivotal role in the installation process. Pressure gradients generated by the imposed suction inside the caisson cavity cause an overall reduction in the lateral soil pressure acting on the caisson wall as well as in the tip resistance. This transient loosening of soil around the caisson wall facilitates caisson penetration into the seabed. However, these effects must be controlled to avoid soil failure due to critical conditions such as piping or loss of soil shear strength, which may cause the installation procedure to fail due to instability of the soil plug trapped inside the caisson cavity. In this paper, we endeavour to study these effects based on the analysis of the normalised seepage problem, assuming the installation process to take place in homogeneous sand. We first investigate the effects of seepage conditions on soil resistance to caisson penetration with a particular focus on how frictional resistance and tip resistance are differently affected. We then consider modes of failure due to soil piping inside the caisson cavity and sliding of soil mass in a failure mechanism where the soil plug inside the caisson cavity is pushed upward. Based on this study, some insight is gained into the critical conditions for piping. These conditions evolve during the installation process as the penetration depth increases under an increasing suction. Upper and lower bounds are also estimated for the critical suction based on an assumed mode of failure using a simple mechanism of rigid blocks. By comparing these modes of failure we conclude that piping is not always the most critical condition. The critical mode of failure for a given soil may change during the installation process and this is highlighted by comparing the critical suction for piping to the suction upper and lower bounds related to shear failure.
\end{abstract}

\section{Introduction}

Suction caisson foundations have been very popular in the oil industry and the current trend is to extend their use to the developing industry of wind farms (Byrne et al., 2002; Byrne and Houlsby, 2003). A suction caisson is an upturned 'bucket' of cylindrical shape made from steel. The thin caisson wall facilitates installation when a pressure differential is induced by suction on the caisson lid, which pushes the caisson to penetrate into the seabed. This is achieved by pumping out the water trapped in the caisson cavity after initial penetration under self-weight. When such procedure is used for caisson installation in sand, suction must be controlled during the whole installation process so that its magnitude does not exceed the critical limit that causes soil failure. It is recognised that within the safety limits against soil piping, porewater seepage induced by suction is beneficial to caisson installation as it

\footnotetext{
* Corresponding author. Tel.: +44 1634 883787; fax: +44 1634883153

E-mail addresses: o.harireche@gre.ac.uk, ouahidharireche@msn.com (0. Harireche).
}

reduces the overall force that resists caisson penetration (Senper and Auvergne, 1982; Tjelta et al., 1986; Erbrich and Tjelta, 1999; Tran et al., 2004; Tran et al., 2005). CPT tests conducted inside the caisson before and after installation, revealed significant loosening of sand (Senders and Randolph, 2009).

The role of porewater seepage has been considered in the development of design procedures for the installation of suction caissons in sand (Tjelta, 1994, 1995; Bye et al., 1995; Erbrich and Tjelta, 1999; Houlsby and Byrne, 2005). Tran and Randolph (2008) conducted a series of model tests in a geotechnical centrifuge to investigate the variation of suction during the installation of caisson foundations in dense sand. They also performed finite element simulations to study the critical hydraulic conditions that develop during caisson installation. Finite element simulations of seepage induced by suction around caisson foundations have also been performed by Zhang et al. (2004). Finite element models with remeshing capabilities have been used to model caisson penetration into clay (Vasquez and Tassoulas, 2000; Maniar and Tassoulas, (2002)). Similar simulations have been performed for sand, where soil behaviour has been described with a 
Drucker-Prager model with cap (Zeinoddini et al., 2011). Ibsen and Thilsted, (2011), used FLAC3D and performed finite difference simulations to study piping limits to suction, which were applied to field installations of suction caissons in sand.

Experimental investigations in dense sand have revealed that soil heave, which is likely to occur during suction assisted installation, sets an additional limit to suction for the required installation depth to be achieved safely (Allersma et al., 1999; Bang et al., 1999; Allersma, 2003; Tran et al., 2004).

Specific soil conditions such as the existence of low permeability silt layers that may affect seepage at some stage of the installation process have been considered by Tran et al., (2007). More recently, Harireche et al. (2013) have considered the effects of suction induced seepage during the installation of caisson foundation in sand with permeability varying with depth.

In the aforementioned literature, the hydraulic gradient on both sides of the caisson wall has been described in terms of an overall value based on the pressure difference between the mudline and the caisson tip. However, due to the importance of the variation of pressure gradient over the caisson penetration depth, it is important to investigate the gradient distribution over the penetration depth throughout the installation process.

In this paper, we consider the excess porewater pressure gradient in terms of the magnitude of its vertical component at each location within the soil mass. This is motivated by the fact that such component defines the seepage force that acts against gravity and directly affects effective stresses.

In the first part of this study we address the effects of excess pore pressure gradients on soil resistance to caisson penetration. A simple finite element procedure is first performed to solve the normalised seepage problem. The variation in effective stresses on both sides of the caisson wall is calculated as a function of the penetration depth and integrated numerically to provide an estimation of the reduction in magnitude of the penetration resisting forces caused by seepage. Problem dimensions are normalised so that the results obtained are independent of caisson prototype and apply to any caisson size. Based on the analysis of the normalised seepage problem, we derive analytical expressions for the magnitudes by which penetration resisting forces are reduced for a given suction and caisson dimensions. The second part of this study is devoted to the investigation of critical soil conditions during caisson installation. In addition to critical conditions for piping, a second mode of failure has been investigated, which is based on a shear failure mechanism. This failure mode has been motivated by the observed deformation process which consists in soil moving into the caisson cavity. For dense sand, such large deformation process results into volume expansion or heave of the soil plug. It is worth examining whether such a deformation process may lead to soil failure that might become more critical compared to the piping condition. Based on the finite element model of the normalised seepage problem, critical conditions for piping and the assumed failure mechanism can be tracked during the whole installation process. Upper and lower bounds to suction have been obtained assuming a simple failure mechanism that consists of two rigid blocks and one single stress discontinuity. Comparison of these bounds to the critical suction for piping revealed that the critical mode of failure may switch from the piping condition to shear failure at some stage of the installation process depending on soil shear strength.

\section{Formulation of the normalised seepage problem}

We consider the model problem of a suction caisson of radius $R$, height $L$ and we denote $h$ the depth of caisson penetration into the seabed. The soil consists of homogeneous sand with permeability $k$ and saturated unit weight $\gamma_{\text {sat }}$. Fig. 1 shows a vertical section

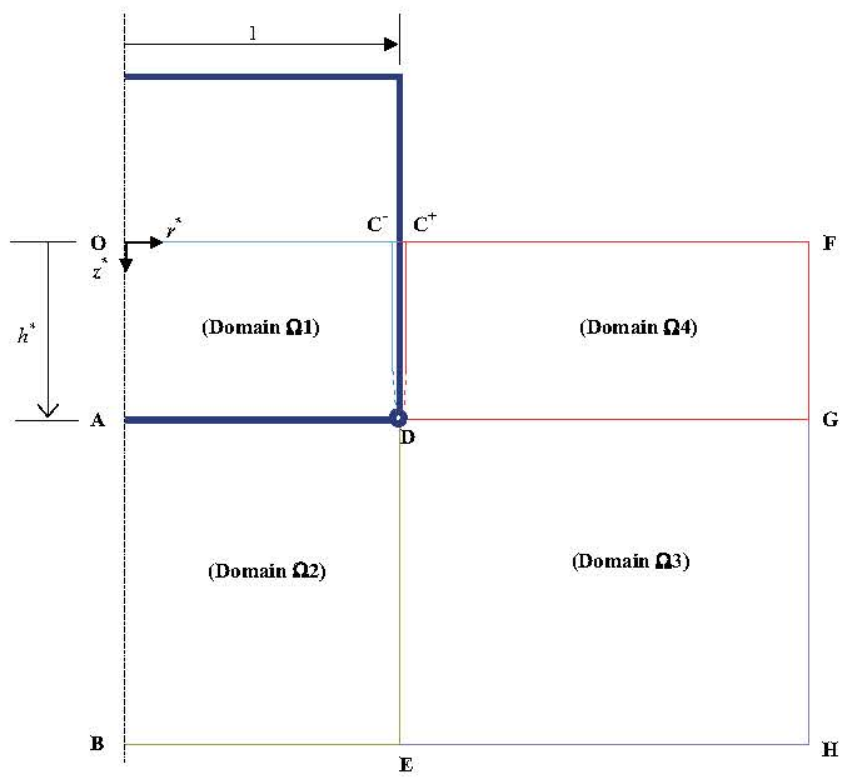

Fig. 1. Normalised geometry.

through the vertical plane of the system caisson-soil where only half of the caisson is represented due to axisymmetric geometry. A cylindrical system with coordinates $r^{*}$ and $z^{*}$ in the meridian plane is adopted for the normalised problem geometry where all dimensions are scaled with respect to the caisson radius.

Before caisson installation, water pressure is in hydrostatic condition with an ambient absolute magnitude at depth $z$, $p_{0}=p_{a t}+\gamma_{w} h_{w}+\gamma_{w} z$, where $p_{a t}$ is the atmospheric pressure, $\gamma_{w}$ the unit weight of water and $h_{w}$ the water height above the mudline. A deviation of the porewater pressure from the hydrostatic value at any location within the soil is referred to as excess porewater pressure and is denoted as $p$. This terminology will be used even in cases where $p$ is negative.

At a certain stage during the caisson installation process, a penetration depth $h$ is reached under the effect of a suction of magnitude $\bar{s}$, assumed constant over the radial distance $\mathrm{OC}^{-}$ (Fig. 1). It is important to note that suction has a negative value; however the magnitude $\bar{s}$ is a positive number. On the mudline boundary $\mathrm{C}^{+} \mathrm{F}$ outside the caisson, and on the boundaries $\mathrm{FH}$ and $\mathrm{BH}$ sufficiently far from the zone of significant suction disturbance, the excess porewater pressure $p$ remains zero.

The porewater seepage is assumed to obey Darcy's law: $\boldsymbol{u}=-k \nabla p$ where $\boldsymbol{u}$ is the porewater velocity field, $k$ the permeability and $\nabla p$ denotes the excess porewater pressure gradient. Assuming volume incompressibility of the porewater flow, the constraint $\operatorname{div} \boldsymbol{u}=0 \quad(\operatorname{div} \equiv(1 / r) \partial / \partial r+(1 / r) \partial / \partial \theta+\partial / \partial z)$, must be superimposed onto Darcy's law which, for a homogeneous soil in axisymmetric conditions, results into the well-known Laplace equation:

$\nabla^{2} p \equiv \partial^{2} p / \partial r^{2}+(1 / r) \partial p / \partial r+\partial^{2} p / \partial z^{2}=0$.

As the caisson penetrates into the seabed, radial porewater flow across the caisson wall is prevented, which is described by the boundary condition on $\mathrm{CD}: \partial p / \partial r=0$ and due to symmetry, this condition must be satisfied on the $z$-axis. In order to obtain the distribution of excess porewater pressure, we divide the soil domain into four regions. Region $\left(\Omega_{1}\right)$ represents soil inside the caisson, $\left(\Omega_{2}\right)$ is the region occupied by soil which passes inside the caisson after further penetration and regions $\left(\Omega_{3}\right)$ and $\left(\Omega_{4}\right)$ are the complementary soil regions outside the caisson.

In order to draw conclusions that are not affected by the prototype dimensions, we adopt the following normalisation 
procedure of the main problem variables and we denote:

$p^{*}=\frac{p}{\bar{s}}$

the dimensionless counterpart of the excess porewater pressure and

$h^{*}=\frac{h}{R}, z^{*}=\frac{z}{R}, r^{*}=\frac{r}{R}\left(0 \leq \mathrm{r}^{*} \leq 1\right.$ on $\mathrm{OC}$ and $1 \leq \mathrm{r}^{*}<\infty$ on $\left.\mathrm{CF}\right)$

the dimensionless counterparts of the caisson penetration depth and the radial and vertical coordinates. The excess porewater pressure $p^{*}$ satisfies the dimensionless equation:

$\nabla^{* 2} p^{*} \equiv \frac{\partial^{2} p^{*}}{\partial r^{* 2}}+\frac{1}{r^{*}} \frac{\partial p^{*}}{\partial r^{*}}+\frac{\partial^{2} p^{*}}{\partial z^{* 2}}=0$

and the boundary conditions:

$p^{*}=-1$ on $\mathrm{OC}^{-}, p^{*}=0$, on $\mathrm{C}^{+} \mathrm{F}, \mathrm{FH}, \mathrm{BH}$ and, $\frac{\partial p^{*}}{\partial r^{*}}=0$ on $\mathrm{CD}$ and $\mathrm{OB}$

The normalised domain in the meridian plane is discretised into four-node bilinear elements. A weak form of Eq. (3) that takes into account the boundary conditions (4) is solved for the unknown excess pore pressure values at nodes. The finite element procedure has the advantage of taking into account soil loosening inside the caisson cavity (domain $\Omega_{1}$ ) in a much more natural way compared to other numerical methods. In the following sections, soil loosening inside the caisson cavity is described using a single constant $k_{f}$ that represents the ratio $k_{i} / k_{0}$ where $k_{i}$ and $k_{0}$ are the respective values of sand permeability inside and outside the caisson (Houlsby and Byrne, 2005). Of particular interest in this analysis are the effects of suction induced seepage on soil resistance to caisson penetration and soil stability during the installation process. The results of this analysis are reported and discussed in the following sections.

\section{Effect of porewater seepage on soil resistance to caisson penetration}

Water seepage caused by suction produces a hydraulic gradient which, on both faces of the caisson wall, varies with depth. Figs. 2a, $\mathrm{c}$ and e show the contours of the normalised excess pore pressure $p^{*}$ for values of the scaled penetration depth $h^{*}=0.2$ (typical of self-weight penetration), $h^{*}=1$ and $h^{*}=2$. These figures show clearly that the pressure gradient, and hence the velocity field, has a direction inside the caisson cavity that tends to become aligned with the $z$-axis as the penetration depth increases.

Figs. $2 b, d$ and $f$ show the contours of the vertical component of the scaled pressure gradient $g^{*} \equiv \partial p^{*} / \partial z^{*}$. It can be observed that the highest gradient magnitudes are concentrated around the caisson tip. At shallow penetration depths, high gradients around the caisson wall affect the whole penetration depth. As the penetration depth increases, these gradients tend to localise around the caisson tip.

Fig. 3a-c show the vertical component of the normalised pressure gradient $g^{*} \equiv \partial p^{*} / \partial z^{*}$ on both sides of the caisson wall as a function of the scaled depth $z^{*}$ for values of the normalised penetration depth $h^{*}=0.2,1.0$ and 2.0. At each of these three normalised penetration depths, the distribution of normalised pressure gradients at each side of the caisson wall is calculated for three values of the permeability ratio, $k_{f}=1,2$ and 3 .

It can be seen that the pressure gradient on each side of the caisson wall is higher at early stages of the installation process. Gradient magnitude on the inner side of the caisson wall decreases as $k_{f}$ is increased, but the opposite trend is observed on the outer side. Maximum values of the gradient occur at the caisson tip and the gradient distribution over the caisson embedment tends to become uniform as the penetration depth increases. The effect of $k_{f}$ on the gradient magnitude on the inner side is not significant around the caisson tip, but the opposite trend is observed on the outer side.

The pressure gradient inside the caisson cavity has positive values, which indicates upward flow and its magnitude is larger than outside the caisson where seepage flow is downward. This clearly indicates that the upward seepage force generated inside the caisson cavity is larger than the downward seepage force that occurs on the outer side. Such a dissymmetry, which is inherited from the distribution of the pressure gradient, causes more reduction in the effective stress inside the caisson than increase in the same stress on the outer side. This in turn results into an overall reduction in the lateral effective pressure on the caisson wall. As a consequence, frictional soil resistance against caisson penetration is reduced. For similar reasons, the resisting force acting against caisson penetration at the caisson tip is also reduced.

These effects are now investigated in more detail in order to identify the proportions to which seepage affects these resisting forces.

In the absence of seepage, when the caisson is pushed into the seabed without disturbing significantly hydraulic conditions, the lateral effective pressure on the caisson wall has the expression:

$\sigma_{h}^{\prime}=K\left(\gamma^{\prime} z+\tilde{\sigma}\right)$

Where $K$ is a lateral earth pressure coefficient. The vertical effective stress near the caisson wall is enhanced by the magnitude $\tilde{\sigma}$ due to the effect of shear resistance that develops on the interface soil-caisson. The lateral pressure coefficient $K$ has generally a larger value compared to the lateral pressure coefficient at rest.

Under seepage conditions produced by an applied suction, the lateral effective pressure acting on the caisson wall, at depth $z$, inside and outside the caisson is respectively expressed as follows:

$\sigma_{h i}^{\prime}(R, z)=K\left(\gamma^{\prime} z-\int_{0}^{z} g_{i}(R, \zeta) d \zeta+\tilde{\sigma}_{i}(R, z)\right)$

$\sigma_{h o}^{\prime}(R, z)=K\left(\gamma^{\prime} z-\int_{0}^{z} g_{0}(R, \zeta) d \zeta+\tilde{\sigma}_{0}(R, z)\right)$

Where $g_{i}(R, \zeta)$ and $g_{0}(R, \zeta)$ denote the vertical component of the pressure gradient on the inner and the outer sides of the caisson wall respectively. If we assume that the enhanced effective stresses $\tilde{\sigma}_{i}$ and $\tilde{\sigma}_{o}$ are not affected by seepage conditions, then the reduction at depth $z$ in the lateral pressure acting on the caisson wall, caused by seepage, is given by

$\Delta \sigma_{h}^{\prime}(R, z)=K\left(\int_{0}^{z} g_{i}(R, \zeta) d \zeta+\int_{0}^{z} g_{0}(R, \zeta) d \zeta\right)$

The pressure gradients can be expressed as follows:

$g_{0}=\frac{\bar{s}}{\bar{R}^{g_{0}}}, g_{i}=\frac{\bar{s}}{\bar{R}^{g_{i}^{*}}}$

Where $g_{0}^{*} \equiv \partial p^{*} / \partial z^{*}$ is the normalised pressure gradient in domains $\left(\Omega_{4}\right),\left(\Omega_{3}\right)$ and $g_{i}^{*} \equiv \partial p^{*} / \partial z^{*}$ denotes the same quantity when evaluated in domains $\left(\Omega_{1}\right)$ and $\left(\Omega_{2}\right)$. Hence, expression (8) can be rewritten under the following form:

$\frac{\Delta \sigma_{h}^{\prime}(R, z)}{K \bar{s}}=L_{i}^{*}\left(z^{*}\right)+L_{o}^{*}\left(z^{*}\right)$

Where, as can be observed from Fig. 3:

$$
\begin{aligned}
L_{i}^{*}\left(z^{*}\right) & \equiv \int_{0}^{z^{*}} g_{i}^{*}\left(1, \zeta^{*}\right) d \zeta^{*}>0, L_{0}^{*}\left(z^{*}\right) \\
& \equiv \int_{0}^{z^{*}} g_{0}^{*}\left(1, \zeta^{*}\right) d \zeta^{*}<0 \text { and }\left|L_{i}^{*}\left(z^{*}\right)\right|>\left|L_{0}^{*}\left(z^{*}\right)\right|
\end{aligned}
$$


a

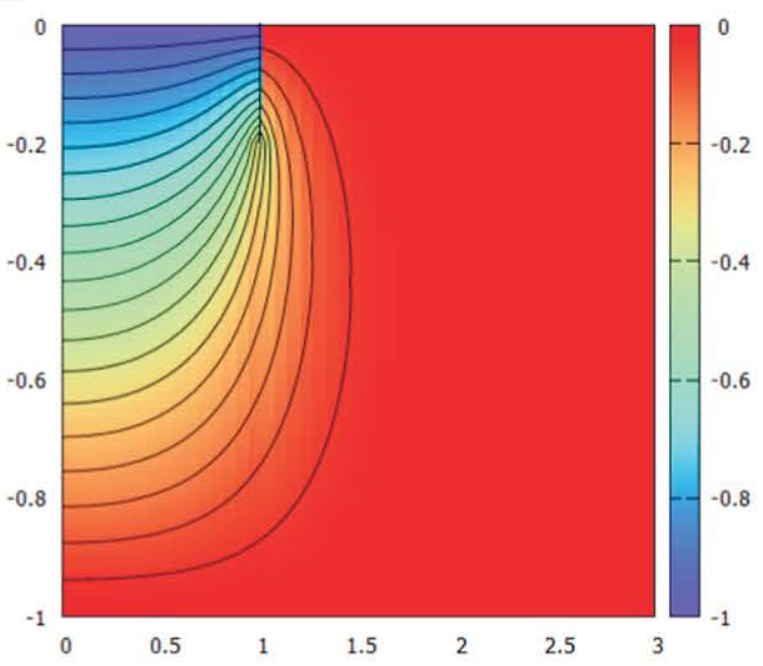

C

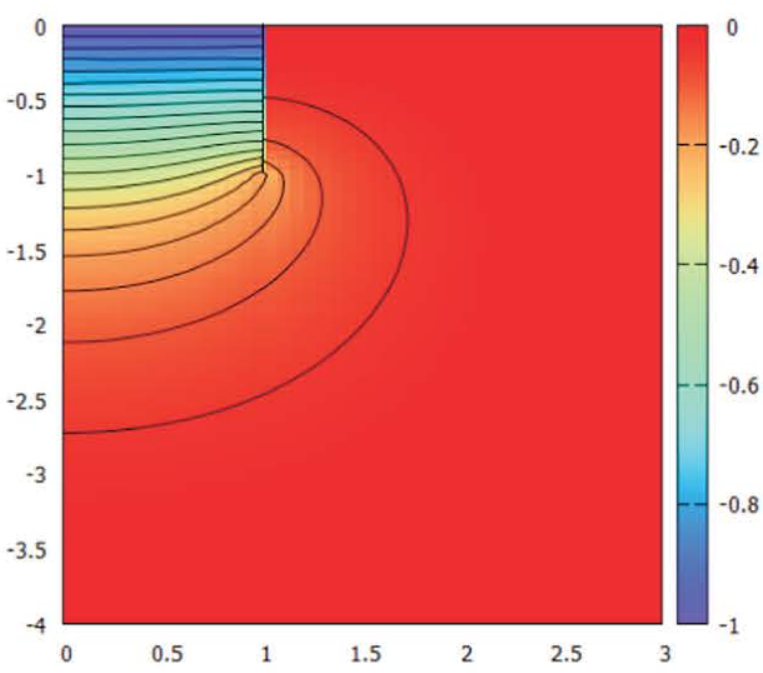

e

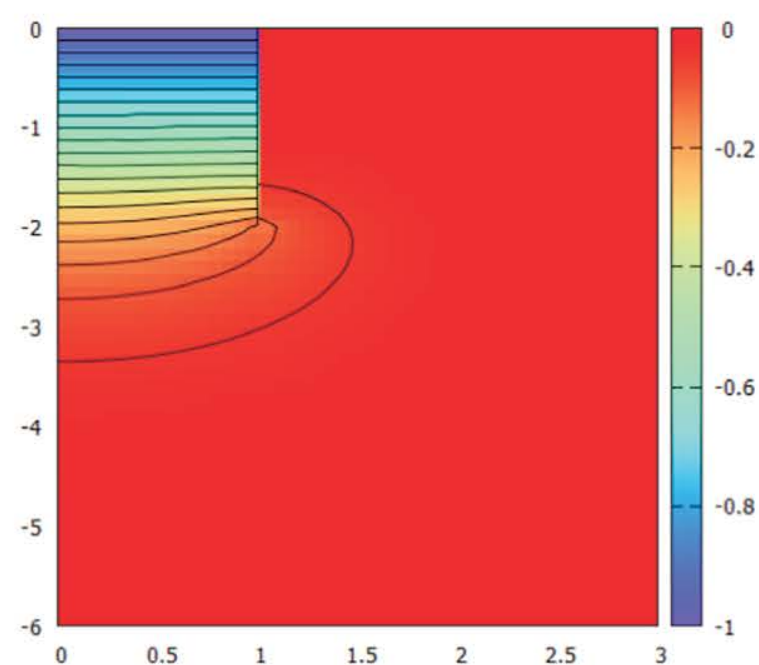

b

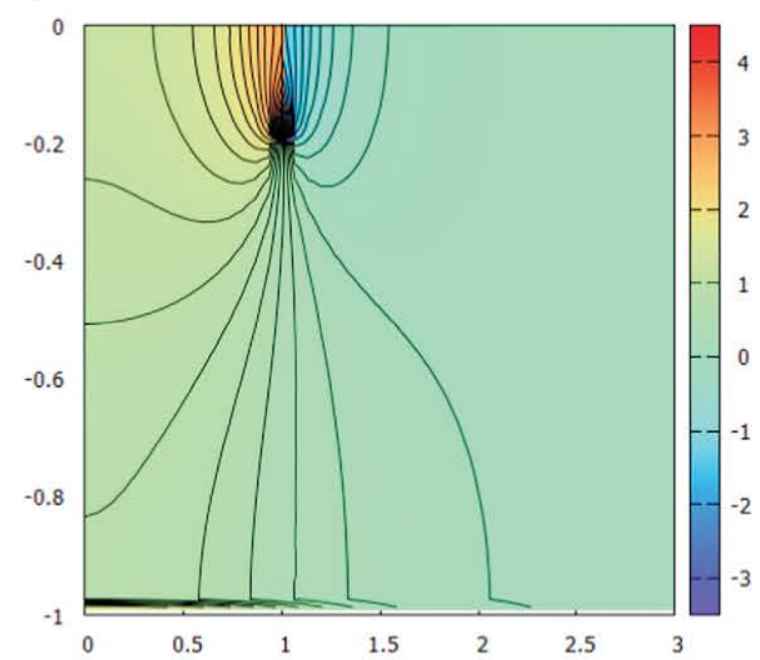

d

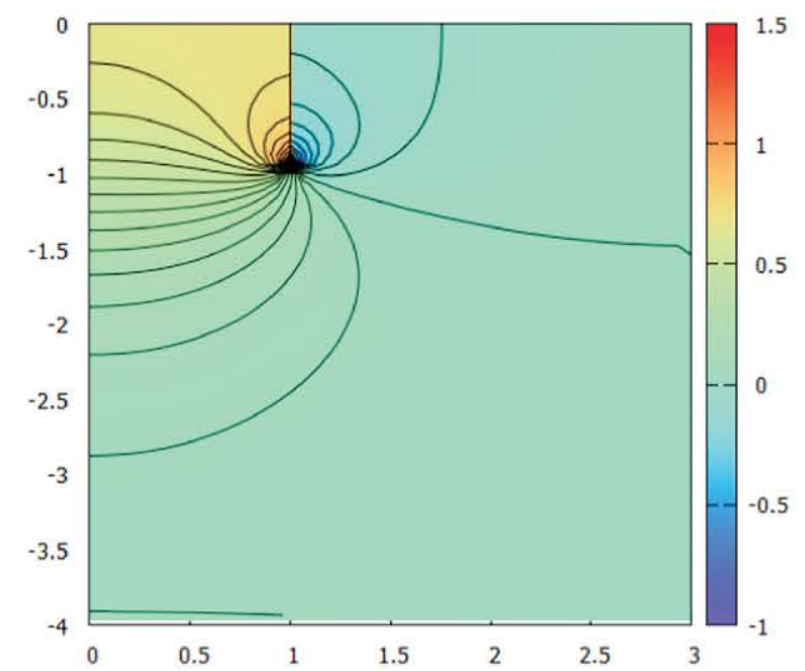

f

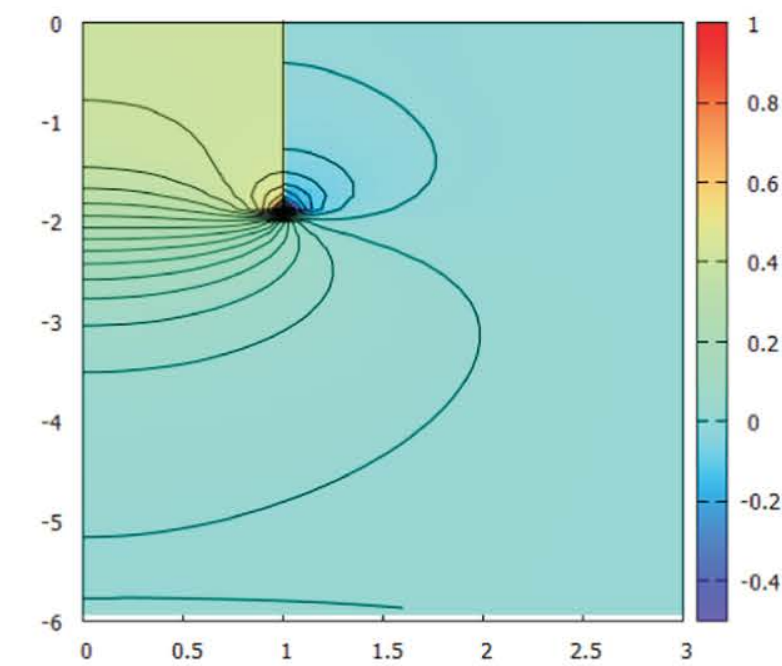

Fig. 2. (a), (c), (e): Normalised excess porewater pressure contours for scaled penetration depths $h^{*}=0.2,1,2$; (b), (d), (f): Contours of normalised pressure gradient. 
a

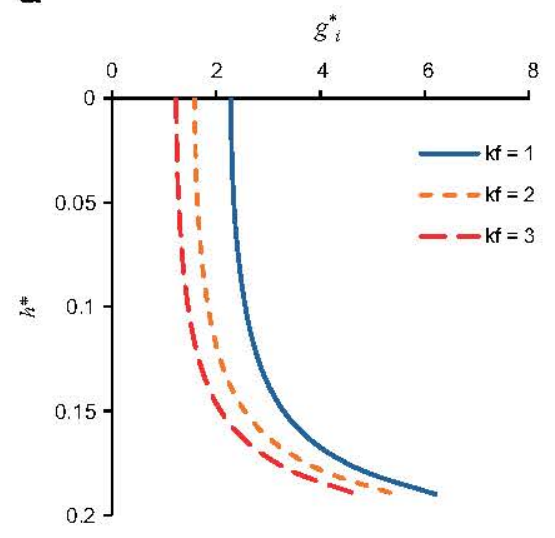

b

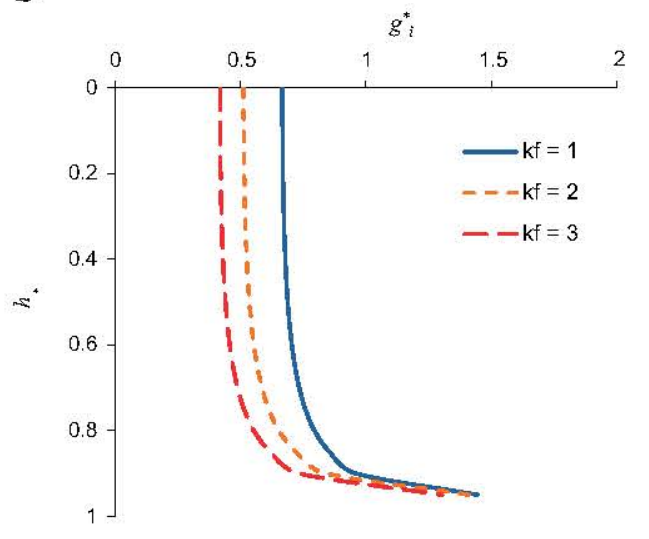

C

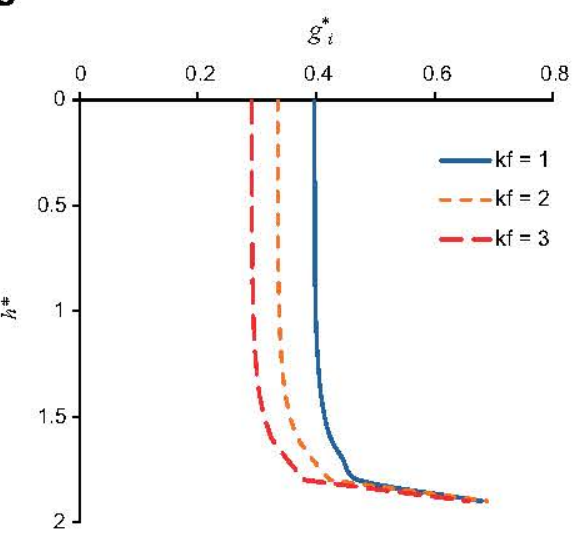

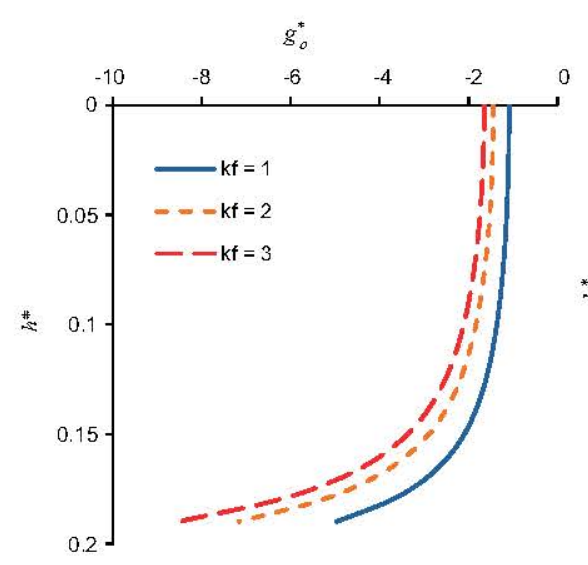

$g_{0}^{*}$
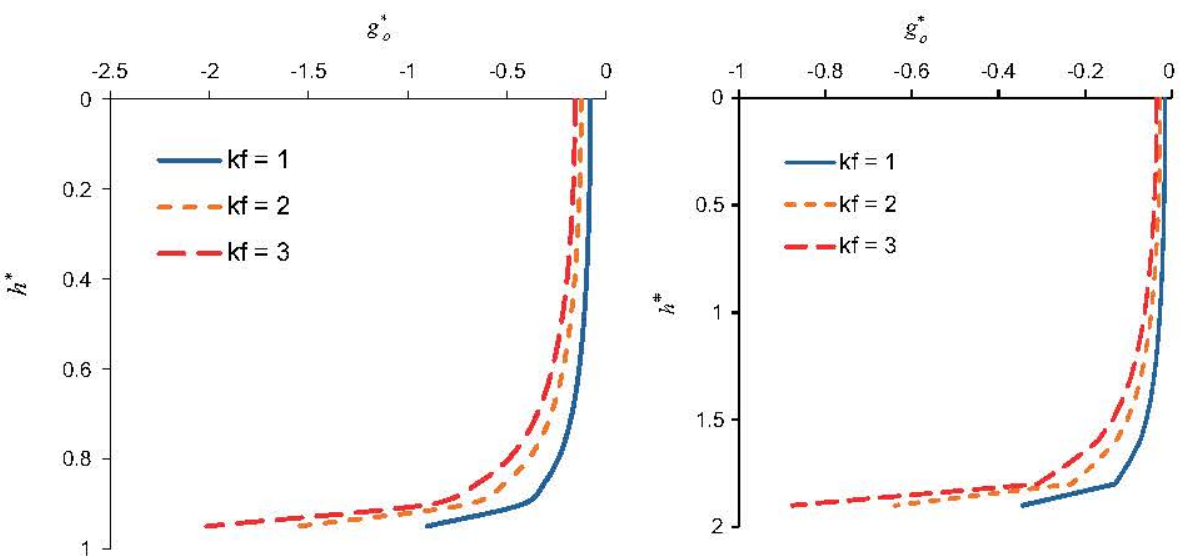

Fig. 3. Dimensionless pressure gradient as a function of scaled depth for different, caisson penetration depths: (a) $h^{*}=0.2$, (b) $h^{*}=1.0,\left(\right.$ c) $h^{*}=2.0$.

Using a numerical calculation of the integrals in (11) on the normalised finite element mesh, we obtain the normalised reduction of the lateral effective stress expressed in (10) as a function of the normalised depth $z^{*}$. As a consequence, seepage causes the frictional resisting force acting on the caisson wall to decrease by a magnitude $\Delta F_{S}$ given as a function of the normalised penetration depth $h^{*}$ by the expression:

$\frac{\Delta F_{S}}{2 \pi R^{2} K \bar{s} \tan \delta}=\int_{0}^{h^{*}}\left[L_{i}^{*}\left(z^{*}\right)+L_{o}^{*}\left(z^{*}\right)\right] d z^{*}$

Where $\delta$ denotes the angle of friction at the interface soil-caisson. It is important to note that on the inner face of the caisson wall, upward seepage causes a loosening of the soil, which in turn reduces the angle of internal friction $\phi^{\prime}$ and increases the lateral pressure coefficient $K$. A more accurate expression of $\Delta F_{s}$ would be obtained if these effects are accounted for. In the present work, soil loosening is reflected qualitatively in the coefficient $k_{f}$ introduced earlier and will be considered with more developments at the end of this section where comparison will be made with some experimental data.

Seepage also causes the vertical effective stress at the caisson tip to decrease, thereby leading to a further reduction in the total resisting force. The resisting force at the caisson tip can be expressed under the form:

$F_{\mathrm{t}}=2 \pi R N_{q} \int_{R_{i}}^{R_{e}} \sigma_{v}^{\prime} d r$

where $N_{q}$ is a bearing capacity factor and $\sigma_{v}^{\prime}$ the vertical effective stress at the caisson tip, which is assumed to vary linearly from $\sigma_{v i}^{\prime}$ inside the caisson (radius $R_{i}$ ) to $\sigma_{\text {vo }}$ outside (radius $R_{0}$ ), and these stresses have the expressions:

$$
\begin{aligned}
& \sigma_{y^{\prime}}^{\prime}(R, h)=\gamma^{\prime} h-\int_{0}^{h} g_{i}(R, \zeta) d \zeta+\tilde{\sigma}_{i}(R, h) \\
& \sigma_{v^{\prime}}^{\prime}(R, h)=\gamma^{\prime} h-\int_{0}^{h} g_{0}(R, \zeta) d \zeta+\tilde{\sigma}_{0}(R, h)
\end{aligned}
$$

Assuming that seepage does not affect the enhanced vertical stress, the resisting force at the caisson tip decreases by the magnitude $\Delta F_{t}$ such that:

$\frac{\Delta F_{t}}{2 \pi R t N_{q} \bar{S}}=\frac{1}{2}\left(L_{i}^{*}\left(h^{*}\right)+L_{o}^{*}\left(h^{*}\right)\right)$

Where functions $L_{i}^{*}\left(z^{*}\right)$ and $L_{0}^{*}\left(z^{*}\right)$ are defined by expressions (11) Expression (16) assumes a linear distribution of the vertical effective stress at the caisson tip through the thickness $t$ of the caisson wall.

The predictions of the reduction in soil resistance due to suction induced seepage expressed by Eqs. (12) and (16) are now compared to the experimental results obtained by Tran and Randolph (2008) (Fig. 4a). These experiments have been performed in a centrifuge on a caisson model made from aluminium, $60 \mathrm{~mm}$ in diameter, $60 \mathrm{~mm}$ in length and $0.3 \mathrm{~mm}$ in wall thickness. The curve corresponding to jacked installation, in Fig. 4a, has been used to identify values for the parameters $K \tan (\delta)$ and $N_{q}$ of 1.02 and 187, respectively. In Fig. $4 \mathrm{a}, q_{r}$ denotes the penetration resistance which is the ratio of the total penetration resisting force over the horizontal cross-sectional area of the caisson.

Based on the experimental results reproduced in Fig. $4 \mathrm{a}$, the difference in penetration resistance, $\Delta q_{r}$, normalised by $2 \bar{s}$, is compared with the theoretical prediction. This comparison is 
a

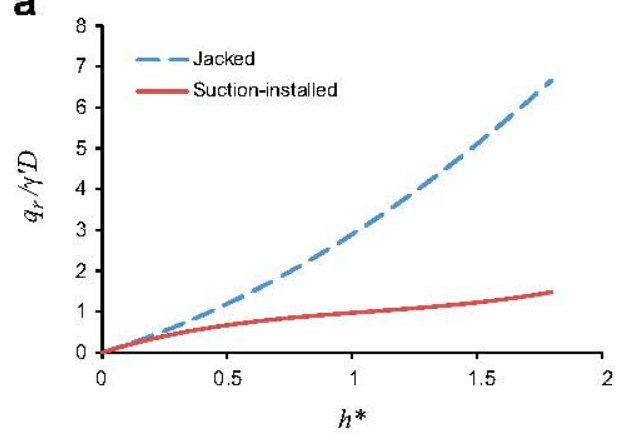

b

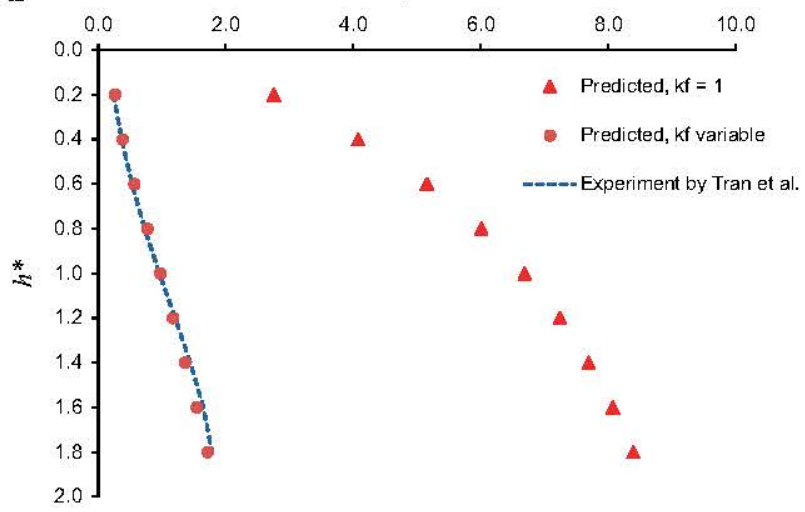

Fig. 4. (a) Experimental data Tran and Randolph (2008). (b) Validation of predicted reduction in penetration resistance for suction-installed caisson.

shown in Fig. 4b, where the experimental data are represented with a discontinuous line. It can be observed that these experimental data do not fit to the theoretical prediction when the effect of soil loosening inside the caisson cavity is not taken into consideration. This is the case $k_{f}=1$ in Fig. $4 \mathrm{~b}$. It is important to note that the discrepancy between experimental data and predicted results increases with the normalised depth, suggesting that, not only $k_{f}$ should be larger than unity, it must also increase during the installation process to reflect continuous soil loosening as suction increases.

Indeed, further testing with values of $k_{f}$ larger than unity but constant throughout the installation process led to the same conclusion. Hence, the permeability factor $k_{f}$ must be variable during installation and must be an increasing function of the normalised penetration depth $h^{*}$. We assume the following simple linear expression:

$k_{f}\left(h^{*}\right)=\alpha h^{*}+k_{f 0}$

After few trials with the simulation of seepage at the first depth increments, values of the parameters $\alpha$ and $k_{f 0}$ have been identified as 3.0 and 1.3 , respectively. The value 1.3 must be interpreted as the permeability ratio when suction is first applied at very shallow penetration depth, after self-weight penetration. It can be observed from the predicted results corresponding to a variable coefficient $k_{f}$ in Fig. $4 \mathrm{~b}$ that in this case, the simulations fit very well to the experimental predictions for the whole installation process. This comparison with experimental data highlights clearly the importance of soil loosening inside the caisson cavity as a result of suction induced seepage during the whole installation process. Expression (17) provides a simple description of the parameter $k_{f}$ which has been adopted in this study to qualitatively reflect such loosening effects. While this validation exercise highlighted the pertinence of the simple assumed form (17) of the parameter $k_{f}$, further experiments are required to justify whether the parameters $\alpha$ and $k_{f o}$ are constants, inherent to the normalised geometry of the caisson problem or dependant on other parameters.

\section{Bounds to suction}

\subsection{Critical suction for piping condition}

We define the maximum suction for piping $s_{\max }$ as the suction that causes the volume of soil inside the caisson cavity to develop piping condition. The suction magnitude that may cause failure of the soil plug should only be a fraction of the maximum value and we refer to it as critical suction. At a generic material point of normalised coordinates $r^{*}, z^{*}$ within the soil inside the caisson, piping takes place when the vertical effective stress becomes zero. This is expressed by the equation:

$\sigma_{v}^{\prime}=\gamma^{\prime} z-\int_{0}^{z} g_{i}(R, \zeta) d \zeta=0$

Hence, the suction magnitude that causes such condition is given by:

$\frac{\bar{s}}{\gamma^{\prime} R}=\frac{z^{*}}{L_{i}^{*}\left(r^{*}, z^{*}\right)}$

where

$L_{i}^{*}\left(r^{*}, z^{*}\right) \equiv \int_{0}^{z^{*}} g_{i}^{*}\left(r^{*}, \zeta^{*}\right) d \zeta^{*}$.

Houlsby and Byrne (2005) have proposed the piping criterion: $\bar{s} /\left(\gamma^{\prime} R\right)=h^{*} /(1-a)$ where $a$ is the magnitude of the normalised pressure at the caisson tip on the inner side; i.e. $a \equiv-p^{*}\left(h^{*}\right)$. The proposed criterion assumes a constant pressure gradient on each side of the caisson wall. In the present study, based on the numerical solution for the normalised seepage problem, condition (19) is an expression of the same criterion that takes into account the actual variation of the pressure gradient as a function of depth. The minimum suction that causes piping condition, which first appears at the caisson tip on the inner side, is given by (19) for $z^{*}=h^{*}$ and $r^{*}=1$, i.e., $\bar{s} /\left(\gamma^{\prime} R\right)=\left(h^{*} / L_{i}^{*}\left(h^{*}\right)\right)$. Hence, to account for the variation of the pressure gradient on the caisson wall, the coefficient $a$ used by Houlsby and Byrne (2005) is to be replaced by the coefficient $\left(1-L_{i}^{*}\left(h^{*}\right)\right.$ ). Fig. 5 shows a comparison of parameters $a$ and $\left(1-L^{*}\right)$. The difference between these two parameters does not seem to be affected by penetration depth

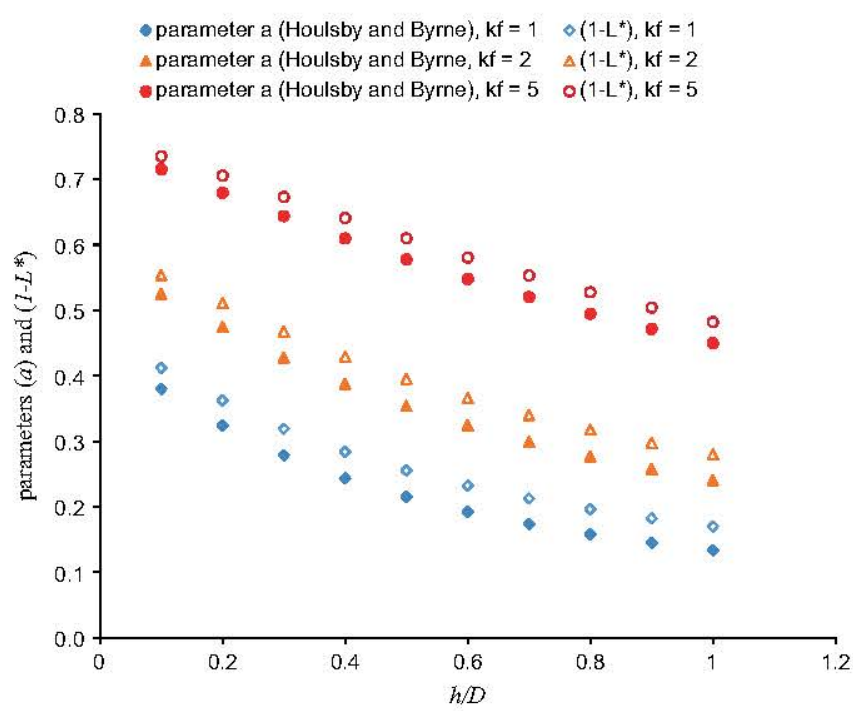

Fig. 5. Comparison of parameters $a$ and $\left(1-L^{*}\right)$ for critical piping condition. 


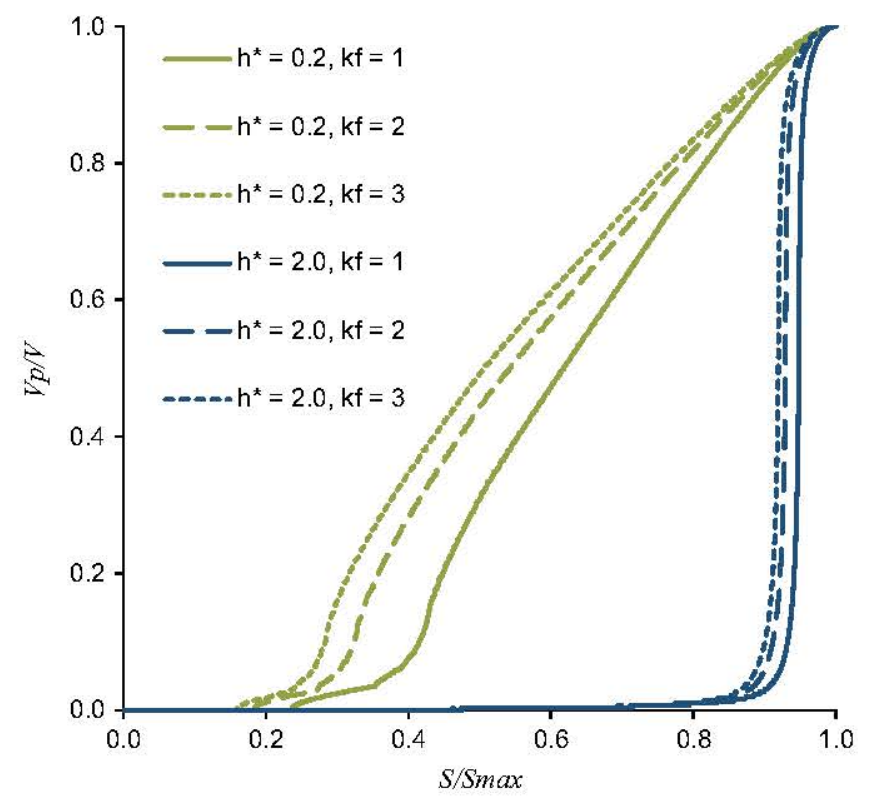

Fig. 6. Proportion of soil volume subject to piping condition as a function of the fraction of maximum suction.

and is not significantly affected by the parameter $k_{f}$. The magnitude of this difference being relatively small, may justify the use of parameter $a$, which is simpler to calculate and conservative as far as piping condition is concerned.

In order to qualitatively estimate the critical suction that causes failure of the soil plug due to piping condition, we investigate the relationship between the suction ratio $s / s_{\max }$ and the ratio $V_{p} / V$ of the volume of soil that develops piping to the total volume of soil inside the caisson cavity. Fig. 6 displays such relationship for different values of the scaled penetration depth. Curves in Fig. 6 are plotted to the resolution of the finite element mesh, by checking condition (19) for each element.

It can be seen that the suction magnitude that causes soil piping to initiate inside the caisson cavity is a higher fraction of the maximum suction as the penetration depth increases. This means that at larger penetration depths, a moderate increase in the suction ratio $s / s_{\max }$ is likely to become critical, compared to similar scenarios at earlier stages of the installation process. Fig. 6 shows clearly how the suction ratio curves become steeper for larger penetration depths, which indicates that the critical suction magnitude becomes closer to the maximum suction as the penetration depth increases.

\subsection{Upper bound}

\subsubsection{Failure mechanism and compatibility conditions}

In the assumed failure mechanism (Fig. 7), the rigid blocks $B_{0}$ and $\mathrm{B}_{\mathrm{i}}$ are subject to displacement increments of magnitudes $\delta u_{B}$ and $\delta u_{B i}$ respectively. Their directions have inclination angles $\theta_{0}$ and $\theta_{i}$ to the horizontal, respectively (Fig. 8). These angles have the expressions:

$\theta_{i}=\frac{\pi}{4}-\frac{\varphi^{\prime}}{2}+\psi \quad$ and $\quad \theta_{0}=\frac{\pi}{4}+\frac{\varphi^{\prime}}{2}-\psi$

Where $\psi$ is the soil dilation angle. Blocks $A_{o}$ and $A_{i}$ are subject to vertical increments of displacement denoted $\delta u_{A 0}$ and $\delta u_{A i}$, respectively. Compatibility conditions (no separation or interpenetration of blocks) impose the following relations on these displacement

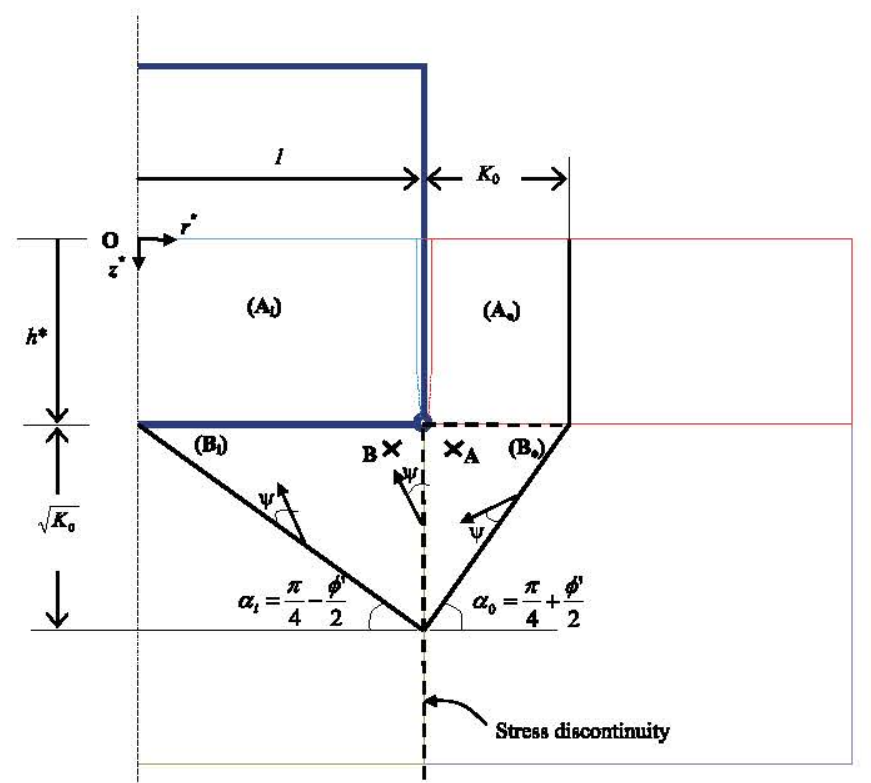

Fig. 7. Assumed failure mechanism and stress discontinuity for the calculation of suction bounds (normalised geometry).

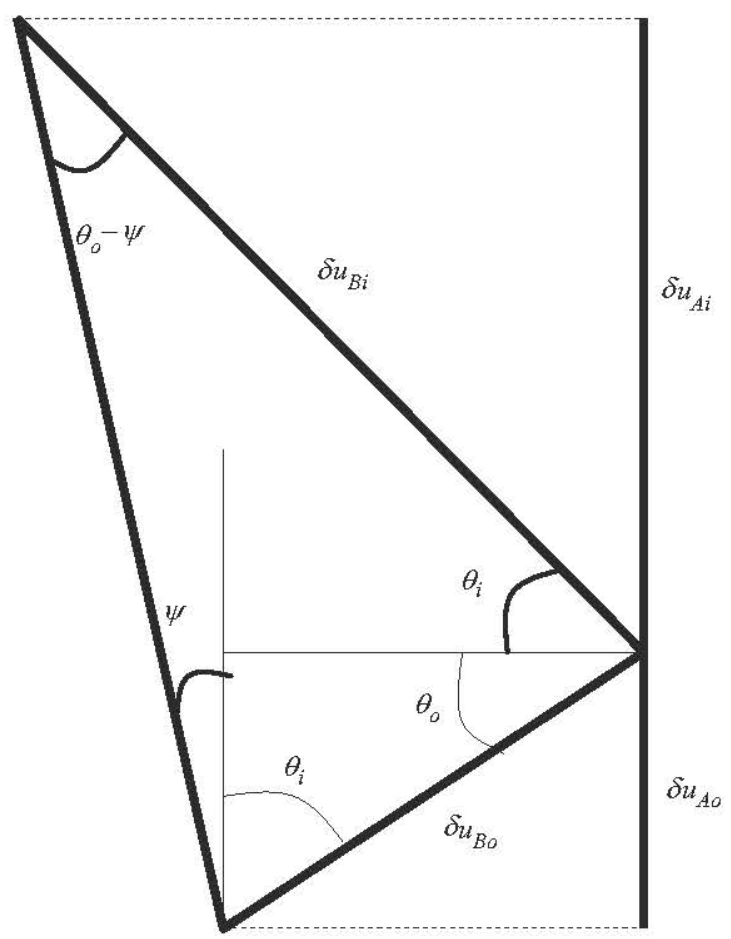

Fig. 8. Compatible displacement increments in the assumed failure mechanism.

increments:

$\delta u_{B o}=\frac{\delta u_{A 0}}{\cos \theta_{i}^{i}}, \delta u_{B i}=\frac{\delta u_{A i}}{\cos \theta_{0}}$ and $\frac{\delta u_{A i}}{\delta u_{A o}}=\xi \equiv \frac{\tan \left(\theta_{i}+\psi\right)}{\tan \theta_{0}}$

The variation of external work $\delta E_{e}$ in these increments of displacement is given by:

$\delta E_{e}=W_{0}^{\prime \prime} . \delta u_{A o}-W_{i}^{\prime \prime} . \delta u_{A i}$

Where $W_{o}^{\prime \prime}$ denotes the magnitude of the effective gravity force acting on soil volume $\Omega_{0}$ outside the caisson (volumes $A_{0}$ and $B_{0}$ ) and $W_{i}^{\prime \prime}$ denotes the magnitude of similar force acting on soil volume $\Omega_{i}$ inside the caisson (volumes $A_{i}$ and $B_{i}$ ). These force 
a

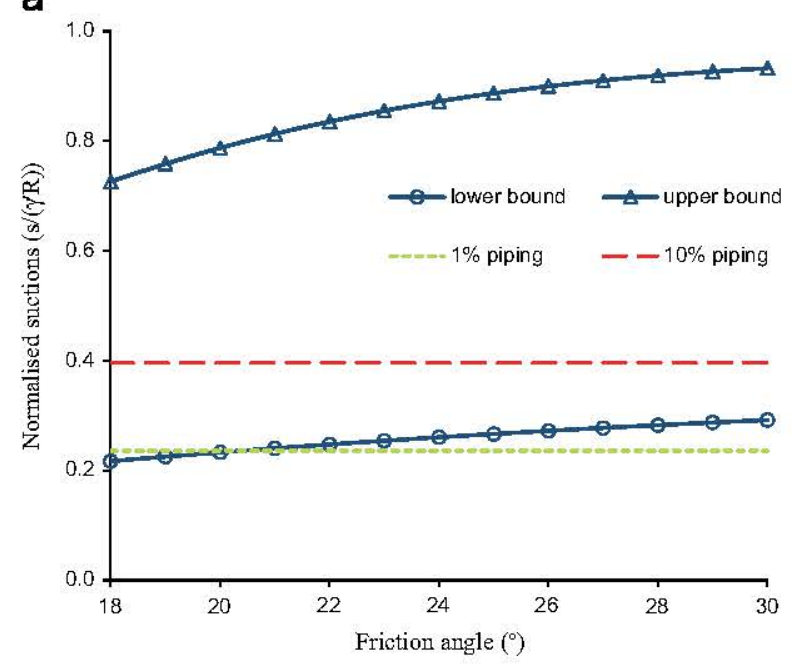

b

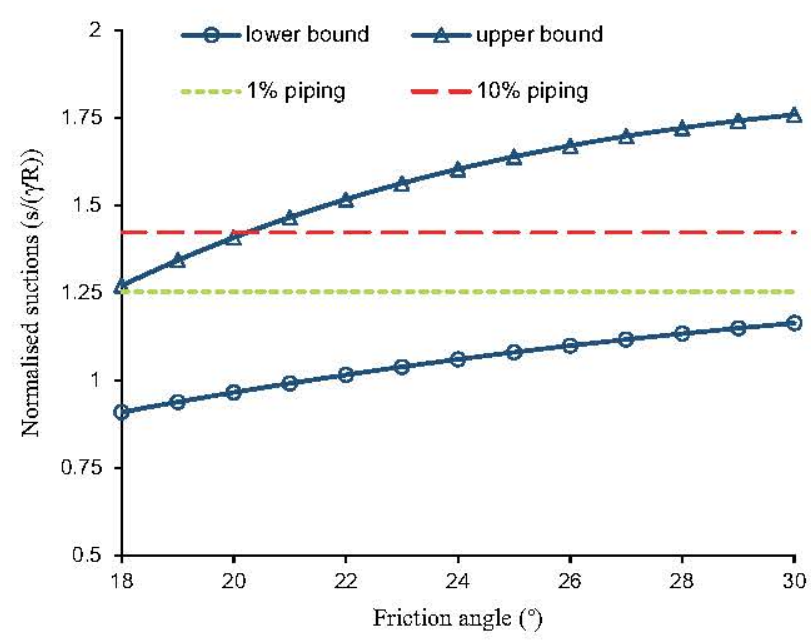

C

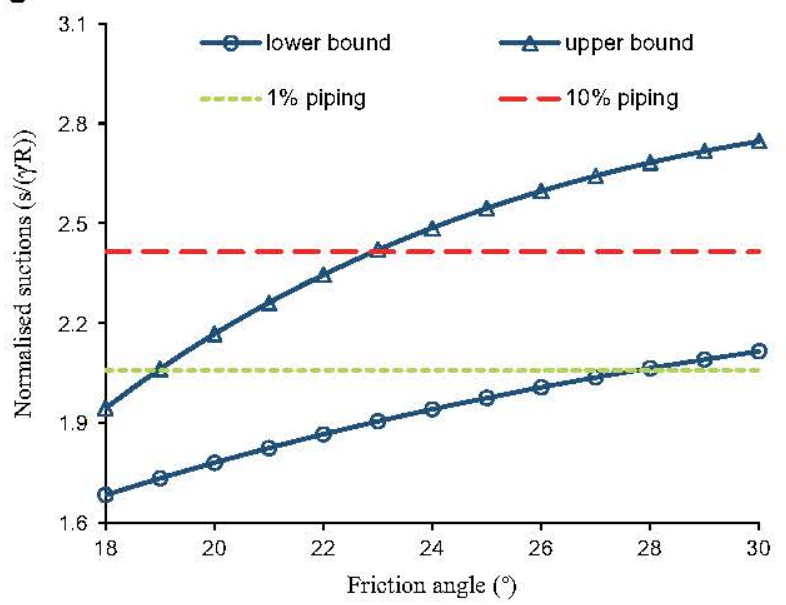

Fig. 9. Upper and lower bounds of normalised suction as functions of the angle of internal friction for different values of the scaled penetration depth: (a) $h^{*}=0.2$, (b) $h^{*}=1.0$, (c) $h^{*}=2.0$.

magnitudes have the expressions:

$W_{o}^{\prime \prime}=\gamma^{\prime} \Omega_{0}-\int_{\Omega_{0}} g_{0} d V, W_{i}^{\prime \prime}=\gamma^{\prime} \Omega_{i}-\int_{\Omega_{i}} g_{i} d V$

Pressure gradients $g_{0}$ and $g_{i}$ in (23) have the expressions (9) in terms of normalised gradients. Using these expressions, the integrals involved in (23) can be rewritten as follows:

$\int_{\Omega_{0}} g_{0} d V=2 \pi R^{2} \bar{s}\left(I_{0}^{*}+J_{0}^{*}\right)$ and $\int_{\Omega_{i}} g_{i} d V=2 \pi R^{2} \bar{s}\left(I_{i}^{*}+J_{i}^{*}\right)$

Where

$I_{0}^{*} \equiv \int_{0}^{h^{*}} \int_{1}^{1+K_{0}} g_{0}^{*} r^{*} d r^{*} d z^{*}, J_{0}^{*} \equiv \int_{h^{*}}^{h^{*}+\sqrt{K_{0}}} \int_{1}^{1+K_{0}-\left(z^{*}-h^{*}\right) \sqrt{K_{0}}} g_{0}^{* *} r^{*} d r^{*} d z^{*}$

$I_{i}^{*} \equiv \int_{0}^{h^{*}} \int_{0}^{1} g_{i}^{*} r^{*} d r^{*} d z^{*}, J_{i}^{*} \equiv \int_{h^{*}}^{h^{*}+\sqrt{K_{0}}} \int_{\left(z^{*}-h^{*}\right) / \sqrt{K_{0}}}^{1} g_{i}^{*} r^{*} d r^{*} d z^{*}$

The volumes $\Omega_{0}$ and $\Omega_{i}$ have the expressions:

$\Omega_{0}=\pi R^{3} \sqrt{K_{0}}\left[\sqrt{K_{0}}\left(2+K_{0}\right) h^{*}+\frac{1}{3}\left(K_{0}^{2}+3 K_{0}+3\right)-1\right]$
$\Omega_{i}=\pi R^{3}\left(h^{*}+\frac{2}{3} \sqrt{K_{0}}\right)$

Suction upper bound $\bar{s}_{u}$ is calculated assuming associated plasticity, i.e., $\phi=\psi$, which leads to a zero-variation in internal work (see for instance Atkinson (1993)). Hence, the expression of the theorem of virtual work reduces to the equation:

$\delta E_{e}=W_{o}^{\prime \prime} \delta v_{0}-W_{i}^{\prime \prime} \delta v_{i}=0$

After substituting the expressions (23) of $W_{o}^{\prime \prime}$ and $W_{i}^{\prime \prime}$ into (29), taking into account (24) and the compatibility conditions (21), we obtain:

$\frac{\bar{S}_{t u}}{\gamma^{\prime} R}=\frac{\Omega_{0}-\xi \Omega_{i}}{2 \pi R^{3}\left[\left(I_{0}^{*}+J_{0}^{*}\right)-\xi\left(I_{i}^{*}+J_{i}^{*}\right)\right]}$

Note that under the assumption of associate plasticity, the assumed failure mechanism is valid for values of the angle of internal friction $\phi^{\prime}$ not exceeding $30^{\circ}$. However, this limitation is not very restrictive in the present study as the purpose of this investigation is to show the relevance of the shear failure mechanism, which is likely to be justified for moderate failure angles, especially due to soil loosening under suction on the inner side of the caisson.

Fig. 9 shows the variation of the normalised suction upper bound as a function of the angle of internal friction $\phi^{\prime}$ for different values of the caisson penetration depth $h^{*}$. 


\subsection{Lower bound}

We select the cylinder of unit radius in the normalised geometry as single stress discontinuity (Fig. 7). The lower bound theorem, which states that the failure criterion should not be violated anywhere within each of the zones separated by the stress discontinuity, where the stress field satisfies equilibrium (Atkinson, 1993), is governed by the state of stress at points A and B at the caisson tip (Fig. 7). The three stresses $\left(\sigma_{v}^{\prime}\right)_{A},\left(\sigma_{v}^{\prime}\right)_{B}$ and $\sigma_{h}^{\prime}$, at the caisson tip, denote the vertical effective stresses at points $A$ and $B$ and the lateral effective stress acting on the discontinuity surface, which remains continuous due to equilibrium. These stresses have the expressions

$\left(\sigma_{\gamma}^{\top}\right)_{A}=\int_{0}^{h}\left(\gamma^{\prime}-g_{0}(R, z)\right) d z=\int_{0}^{h^{*}}\left(\gamma^{\prime}-\bar{s} g_{0}^{*}\left(1, z^{*}\right)\right) R d z^{*}=R \gamma^{\prime} h^{*}-\bar{s} L_{0}^{*}\left(h^{*}\right)$

$\left(\sigma_{v}^{\dagger}\right)_{B}=\int_{0}^{h}\left(\gamma^{\top}-g_{i}(R, z)\right) d z=\int_{0}^{h^{*}}\left(\gamma^{\top}-\overline{\bar{S}} g_{i}^{*}\left(1, z^{*}\right)\right) R d z^{*}=R \gamma^{\top} h^{*}-\bar{S}_{i}^{*}\left(h^{*}\right)$

$\sigma_{h}^{\prime}=K_{0}\left(\sigma_{v}^{\prime}\right)_{A}=\frac{1}{K_{0}}\left(\sigma_{v}^{\prime}\right)_{B}$

Eq. (33) holds when soil yields on both sides of the stress discontinuity and points $A$ and $B$ are in active and passive states respectively. The functions $L_{o}^{*}\left(z^{*}\right)$ and $L_{i}^{*}\left(z^{*}\right)$ are given by expressions (11).

By substituting (31) and (32) into (33) we obtain an expression for the suction lower bound based on the assumed stress discontinuity:

$\frac{\bar{s}_{l}}{\gamma^{\prime} R}=\frac{h^{*}\left(1-K_{0}{ }^{2}\right)}{L_{i}^{*}\left(h^{*}\right)-K_{0}{ }^{2} L_{0}^{*}\left(h^{*}\right)}$

Fig. 9 shows the normalised suction lower bound as a function of the soil internal angle of friction $\phi^{\prime}$ for different values of the normalised penetration depth $h^{*}$.

Fig. 9 also displays the normalised suction magnitudes that correspond to $1 \%$ and $10 \%$ of the soil plug volume affected by the piping condition. It can be seen that as the penetration depth increases, shear strength tends to govern soil stability. For instance, at a normalised depth $h^{*}=2$ (Fig. 9c), the suction ratio that causes $10 \%$ of soil piping exceeds the suction upper bound for a range of friction angle values up to $23^{\circ}$. This shows clearly that, while piping governs the critical soil condition during the early stages of caisson installation, such condition may switch to a failure mechanism governed by shear strength at larger penetration depths. Hence, both mechanisms must be considered when estimating a safe suction profile for caisson installation in sand. This justifies the need for further investigation regarding the modes of soil failure during caisson installation in sand.

\section{Conclusion}

This investigation has been motivated by the need to develop rational procedures to predict the effects of suction-induced seepage on soil conditions during caisson installation in sand. The numerical solution of the normalised model problem for seepage around a caisson foundation has first been obtained. Normalised pressure gradients have been used to study soil resistance to caisson penetration and critical conditions for soil failure. The present analysis takes into account the actual variation in pressure gradient on both sides of the caisson wall.

Expressions for the magnitudes by which penetration resisting forces reduce due to seepage have been derived. These expressions can be evaluated at different penetration depths with the help of the numerical solution of the normalised seepage problem. Critical conditions for soil piping have been investigated in conjunction with a second shear failure mode affecting the soil plug. Piping is found to govern the critical failure condition at the early stages of the installation process. The failure criterion might switch to a mechanism governed by shear failure at larger penetration depths for sufficiently low shear strength. These findings justify the need for further investigation of the modes of soil failure during caisson installation in sand. Extension of the present work may consist in considering more appropriate failure mechanisms and stress discontinuities to overcome the limitation on the soil angle of internal friction set by the simple mechanism adopted in this work. Finally, the effect of low permeability layers, such as the existence of clay substratum within the installation depth, may be considered as it is expected to affect the critical installation conditions described in this paper.

\section{Acknowledgement}

Funding of a PhD scholarship by the University of Greenwich to support the second author is gratefully acknowledged.

\section{References}

Allersma, H.G.B., Kirstein, A.A.R.B., Brinkgreve, T.S., 1999. Centrifuge and numerica modelling of laterally loaded suction piles. In: Proceedings of the Ninth International offshore and Polar Engineering Conference. Brest, France, vol. 1, pp. 711-717.

Allersma, H. G. B., 2003. Centrifuge research on suction piles: installation and bearing capacity. In: Proceedings BGA International Conference on Foundations: Innovations, Observations, Design and Practice. Dundee, UK, pp. 91-98.

Atkinson, J.H., 1993. An Introduction to the Mechanics of Soils and Foundations: Through Critical State Soil Mechanics. McGraw Hill International Series in Civil Engineering, UK p. 360.

Bang, S., Cho, Y., Preber, T., Thomason, J., 1999. Model testing and calibration of suction pile installation in sand. In: Proceedings of the 11th Asian Regional Conference on Soil Mechanics and Geotechnical Engineering. Seoul, Korea, pp. 235-256.

Bye, A., Erbrich, C. T., Rognlien, B., Tjelta, T. I., 1995. Geotechnical design of bucket foundations. Offshore Technology Conference. Paper OTC 7793. Houston, TX 16pp.

Byrne, B.W., Houlsby, G.T., Martin, C., Fish, P., 2002. Suction caisson foundations for offshore wind turbines. Wind Eng. 26 (3), 145-155.

Byrne, B.W., Houlsby, G.T., 2003. Foundations for offshore wind turbines. Philos. Trans. R. Soc. London Ser. A 361, 2909-2930.

Erbrich, C.T., Tjelta, T.I., 1999. Installation of Bucket Foundations and Suction Caissons in Sand: Geotechnical Performance. Offshore Technology Conference. Paper OTC. Houston, TX 10990, 11pp.

Harireche, O., Mehravar, M., Alani, A.M., 2013. Suction caisson installation in sand with isotropic permeability varying with depth. Applied Ocean Research 43 $256-263$.

Houlsby, G.T., Byrne, B.W., 2005. Design Procedures for Installation of Suction Caissons in Sand. In: Proceedings of the Institution of Civil Engineers, Geotechnical Engineering. 158(3), pp. 135-144.

Ibsen, L.B., Thilsted, C.L., 2011. Numerical study of piping limits for suction installation of offshore skirted foundations and anchors in layered sand. In: Taylor, Group, Francis (Eds.), Frontiers in Offshore Geotechnics II - Gouvernec \& White, London, ISBN: 978-0-415-58480-7.

Maniar, D. R., Tassoulas, J. L., 2002. Non-linear finite element simulation of suction caissons. In: Proceedings of the 15th ASCE Engineering Mechanics Conference, 2-5 June 2002. Columbia University, New York.

Senders, M., Randolph, M.F., 2009. CPT-based method for the installation of suction caissons in sandjournal of Geotechnical and Geoenvironmental EngineeringASCE, pp. 14-25.

Senper, D., Auvergne, G.A, 1982. Suction anchor piles-a proven alternative to driving or drilling. Offshore Technology Conference. Houston, USA. OTC 4206

Tjelta, T.I., Guttormsen, T.R., Hermstad, J., 1986. Large-scale penetration test at a deepwater site. Offshore Technology Conference, Paper OTC 5103. Houston, TX $12 \mathrm{pp}$.

Tjelta, T.I., 1994. Geotechnical aspects of bucket foundations replacing piles for the Europipe 16/11-E Jacket offshore Technology Conference. Paper OTC 7379 Houston, TX, 10pp.

Tjelta, T.I., 1995. Geotechnical experience from the installation of the Europipe jacket with bucket foundations. Offshore Technology Conference. Paper OTC 7795, Houston, TX, 12pp. 
Tran, M. N., Randolph, M. F. Airey, D. W., 2004. Experimental study of suction installation of caissons in dense sand. In: Proceedings of the 23rd International Conference on Offshore Mechanics and Arctic Engineering. Vancouver, Canada, Paper number: OMAE04-51076.

Tran, M. N., Randolph, M. F., Airey, D. W., 2005. Study of seepage flow and sand plug loosening in installation of suction caissons in sand. In: Proceedings of the 15th International Offshore and Polar Engineering Conference, 19-24 June, 2005. Seoul, South Korea, pp. 516-521

Tran, M.N., Randolph, M.F., Airey, D.W., 2007. Installation of suction caissons in sand with silt layers. J. Geotech. Geoenviron. Eng. 133 (10), 1183-1191.

Tran, M.N., Randolph, M.F., 2008. Variation of suction pressure during caisson installation in sand. Géotechnique 58 (1), 1-11.
Vasquez, L. F., Tassoulas, J. L., 2000. Finite element analysis of suction piles. In: Proceedings of the European Congress on Computational Methods in Applied Sciences and Engineering, Barcelona, 11-14 September 2000.

Zhang, S., Zheng, Q, Liu, X., 2004. Finite element analysis of suction penetration seepage field of bucket foundation platform with application to offshore oilfield development. Ocean Eng. 31, 1591-1599.

Zeinoddini, M., Mousavi, S. A., Abdi. M. R., 2011. Simulation of suction caisson penetration in seabed using an adaptive mesh technique. In: Proceedings of the 12th East Asia-Pacific Conference on Structural Engineering and Construction. Procedia Engineering 14, pp. 1721-1728. 